\title{
Design of a Linearly Polarized HMSIW U-Slot Antenna
}

\author{
Patrik HUBKA, Jaroslav LACIK \\ Dept. of Radio Electronics, Brno University of Technology, Technicka 12, 61600 Brno, Czech Republic \\ xhubka00@stud.feec.vutbr.cz, lacik@vut.cz \\ Submitted July 21, 2020 / Accepted June 25, 2021
}

\begin{abstract}
In this paper, a characteristic modal analysis and a design guide of a linearly polarized HMSIW U-slot antenna is proposed. The presented characteristic modal analysis of the antenna explains its multi-modal behavior in the centimeter frequency band. Further, in this paper there is a design guide of the antenna for several dielectric substrates. Exploitation of the design guide is demonstrated on the design of several antenna examples which are finally experimentally verified in a laboratory environment.
\end{abstract}

\section{Keywords}

HMSIW, slot antenna, characteristic modal analysis, design guide

\section{Introduction}

The rapid development of microwave components demands minimization of feeding networks. In 1998, a microwave structure called Substrate Integrated Waveguide (SIW) was introduced [1]. SIW is based on the conventional rectangular waveguide and preserves its advantages, such as low losses, high quality factor and selfconsistent electrical shielding. The main disadvantage of SIW is larger physical dimensions especially at lower frequencies. Reduction of physical size of SIW is needed in order to achieve good compactness. The best solution in reducing SIW size is by exploiting half-mode structure SIW (HMSIW) technology [2]. The HMSIW retains all advantages of SIW technology and it reduces the physical size by nearly half.

In [3], a linearly polarized (LP) narrow rectangular slot HMSIW antenna is presented. Unfortunately, the impedance bandwidth of the antenna is only $1.1 \%$ for a reflection coefficient less than $-10 \mathrm{~dB}$. An E-shaped slot is presented in [4]. The measured gain of the antenna is $4.6 \mathrm{~dB}$ and the impedance bandwidth is about $1 \%$. In [5], a HMSIW Z-slot is proposed. The impedance bandwidth of the antenna is $3.5 \%$. The measured peak gain is $5.6 \mathrm{dBi}$. The antenna achieves a very low cross-polarization level. Another slot antenna is proposed in [6]. The simulated peak gain is only $2.83 \mathrm{dBi}$ and impedance bandwidth is about $1 \%$. In [7], a linearly polarized cavity-backed antenna based on HMSIW technology is presented. The impedance bandwidth of the antenna is $4.9 \%$ and the gain is about
6.7 $\mathrm{dBi}$. A dual band cavity-backed antenna is presented in [8]. The measured gain of the antenna is $5.9 \mathrm{dBi}$ and $5.1 \mathrm{dBi}$. The measured impedance bandwidth of the antenna is $2.2 \%$ and $2.4 \%$. Another cavity-backed HMSIW antenna is introduced in [9]. The antenna is composed of a main HMSIW antenna and a slot placed in its ground plane. The antenna achieves a measured gain of $3.64 \mathrm{dBi}$ and impedance bandwidth of $1.22 \%$. An HMSIW triangular, semi-circular and semi-hexagonal antenna is presented in [10], [11] and [12]. These antennas could be modified by adding a slot, but the performance of these antennas is worse compared to the antennas without the slot.

To obtain circular polarization (CP) with these antenna concepts, an orthogonal slot is etched at the top wall of the HMSIW [13]. Another way how to obtain CP, is utilizing two crossed slots [14].

To improve the impedance bandwidth of conventional cavity backed antennas, loading the aperture with a patch is used, presented in [15]. Depending on the shape of the patch, linearly or circularly polarized waves can be radiated. For both types of antennas, the measured impedance bandwidth is about $10.0 \%$. The measured peak gain for the linearly and circularly polarized antenna is $7.5 \mathrm{dBi}$ and $6.8 \mathrm{dBi}$, respectively. A very interesting solution for obtaining wider impedance bandwidth is the exploitation of a dielectric resonator to obtain an HMSIW dielectric resonator antenna (DRA) [16]. The antenna consists of a transverse slot or a pair of crossed slots used for feeding a dielectric resonator in order to obtain LP or CP, respectively. The DRA achieves an impedance bandwidth of $24.0 \%$ and gain $5.5 \mathrm{dBi}$ for LP version.

The HMSIW H-plane horn antenna is introduced in [17]. The size reduction is around $32 \%$ compared to the SIW version of a horn antenna. The antenna radiates linearly polarized waves in the H-plane with a measured gain of $5.88 \mathrm{dBi}$. The measured impedance bandwidth is only $1.18 \%$.

A circularly polarized SIW square ring-slot antenna is published in [18]. Based on its design, an HMSIW U-slot antenna with LP [19] and CP [20] are proposed. However, a general description of the HMSIW U-slot antenna is necessary. In this article, we present an extension of our work [19] focusing on the modal analysis and the design guide of a linearly polarized HMSIW antenna. In Sec. 2, a brief description of the discussed antenna is given. In 
Sec. 3 , the modal analysis is proposed. The modal analysis is composed of the modal significances, the surface currents and radiation patterns. Thanks to the modal analysis, we better understand the behavior of the antenna especially at higher frequencies. Section 4 is focused on the design guide (DG) of the discussed antenna. The DG is successfully verified on several dielectric substrates.

\section{U-Slot Antenna Configuration}

The antenna is depicted in Fig. 1. It was firstly published in [19]. The single-layer antenna structure is composed of a dielectric substrate and two metal sheets. The dielectric substrate is defined by the physical dimensions (height $h$, length $L$ and width $W$ ), relative permittivity $\varepsilon_{\mathrm{r}}$ and the loss tangent $\tan (\delta)$. The bottom side of the dielectric substrate is fully coated with metal. A U-slot antenna with GCPW (grounded coplanar waveguide) transition is printed on the top side of the dielectric substrate. The Uslot antenna is etched at the distance $L_{\text {viaY }}$ from the row of vias of the HMSIW in y-direction and at the distance $L_{\mathrm{viaX}}$ from the shorted end of the HMSIW in the $\mathrm{x}$-direction. The U-slot, which is defined by the physical dimensions $L_{\text {SLOT-X }}$ and $L_{\text {SLOT-Y }}$, is twice shorted by the shorts $S_{1}$ and $S_{2}$ with the width $W_{\text {SHORT1 }}$ and $W_{\text {SHORT2 }}$, respectively. The physical dimensions of the U-lot antenna are summarized in Tab. 1 published in [19].

\section{Characteristic Modal Analysis}

To carry out characteristic modal analysis (CMA) of the antenna, the antenna is tuned at an operating frequency of $10 \mathrm{GHz}$ with the help of the time domain solver of CST Microwave Studio (MWS). The CMA was performed using CST MWS and FEKO. In FEKO, the antenna was analyzed with infinite lossless substrate and infinite ground. In CST MWS, the antenna was analyzed with finite lossless substrate and infinite ground. The CST MWS model of the antenna is closer to a real model of the antenna. Thus, more accurate results of modal analysis are expected in CST MWS. Therefore, only CST MWS results are shown. The used substrate is ARLON CuClad217 with relative permittivity $\varepsilon_{\mathrm{r}}=2.17$, tangent loss $\tan (\delta)=0.0009$ and height $h=1.524 \mathrm{~mm}$. The physical dimensions of both antennas are the same.

The CMA was analyzed in the frequency range (318) GHz. Figure 2 depicts the first 10 modal significances (MSs) in comparison to the S-parameter calculated in (a) CST and in (b) FEKO. Thanks to the different models used in the calculations, the resonant frequencies of the MSs are shifted especially at lower frequencies. Based on the depicted MSs, all these modes are above 0.8 over the entire frequency range, thus they can be excited effectively. At the lower frequencies, the MSs are farther from each other, thus the antenna has narrow impedance bandwidth. On the other hand, the antenna has the MSs closer to each other at the higher frequencies, thus the antenna has potential to operate within a wider frequency band.

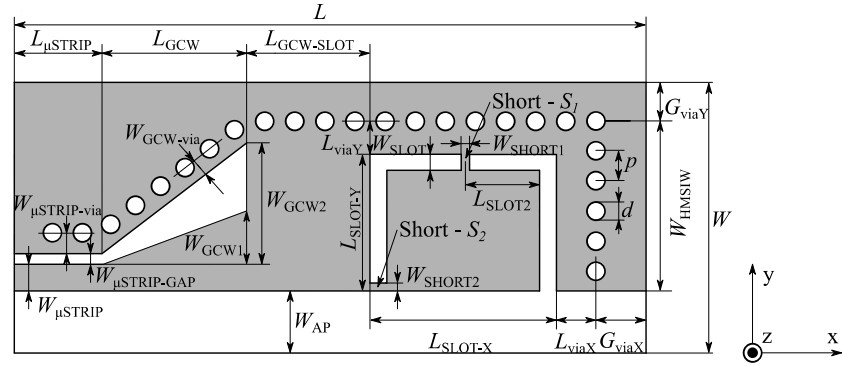

(a)

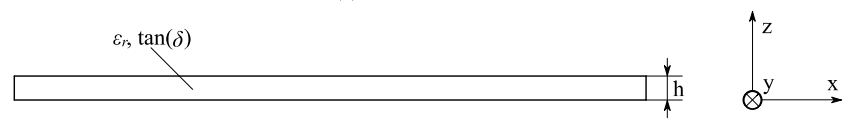

(b)

Fig. 1. HMSIW U-shape slot antenna: (a) Top. (b) Side view.

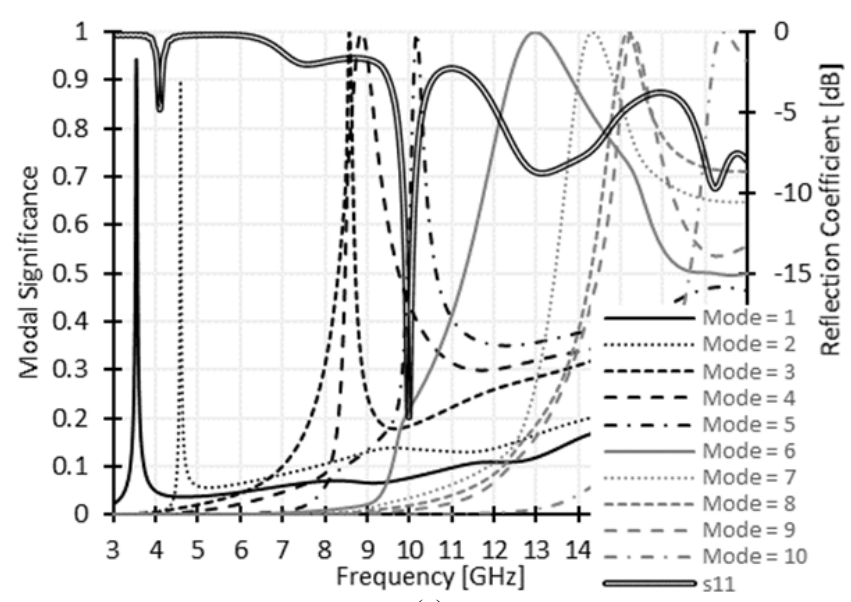

(a)

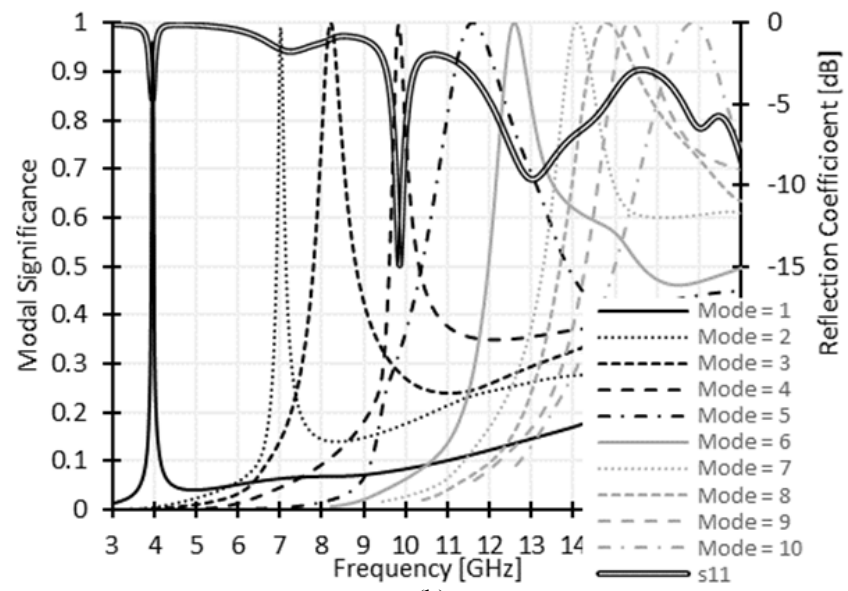

(b)

Fig. 2. CMA - modal significance: (a) CST, (b) FEKO.

\subsection{Surface Currents and Radiation Patterns Calculated in CST MWS}

Figure 3 illustrates the modal currents of the MSs calculated in CST MWS. $J_{n}$ represents the modal surface current of mode $n$. The resonating frequencies of every $J_{n}$ are listed in Tab. 1. It is obvious that the part of the surface currents $J_{4}, J_{6}, J_{8}$ and $J_{10}$ are out of the antenna area bounded by the HMSIW. Thus, these modal currents are not suitable for excitation. 


\begin{tabular}{|c|c|c|c|c|c|}
\hline \# mode & 1 & 2 & 3 & 4 & 5 \\
\hline$f_{\mathrm{r}}[\mathbf{G H z}]$ & 3.54 & 4.59 & 8.58 & 8.87 & 10.17 \\
\hline$\#$ mode & 6 & 7 & 8 & 9 & 10 \\
\hline$f_{\mathrm{r}}[\mathbf{G H z}]$ & 12.98 & 14.33 & 15.17 & 15.27 & 17.43 \\
\hline
\end{tabular}

Tab. 1. Resonant frequency of the exited modes.
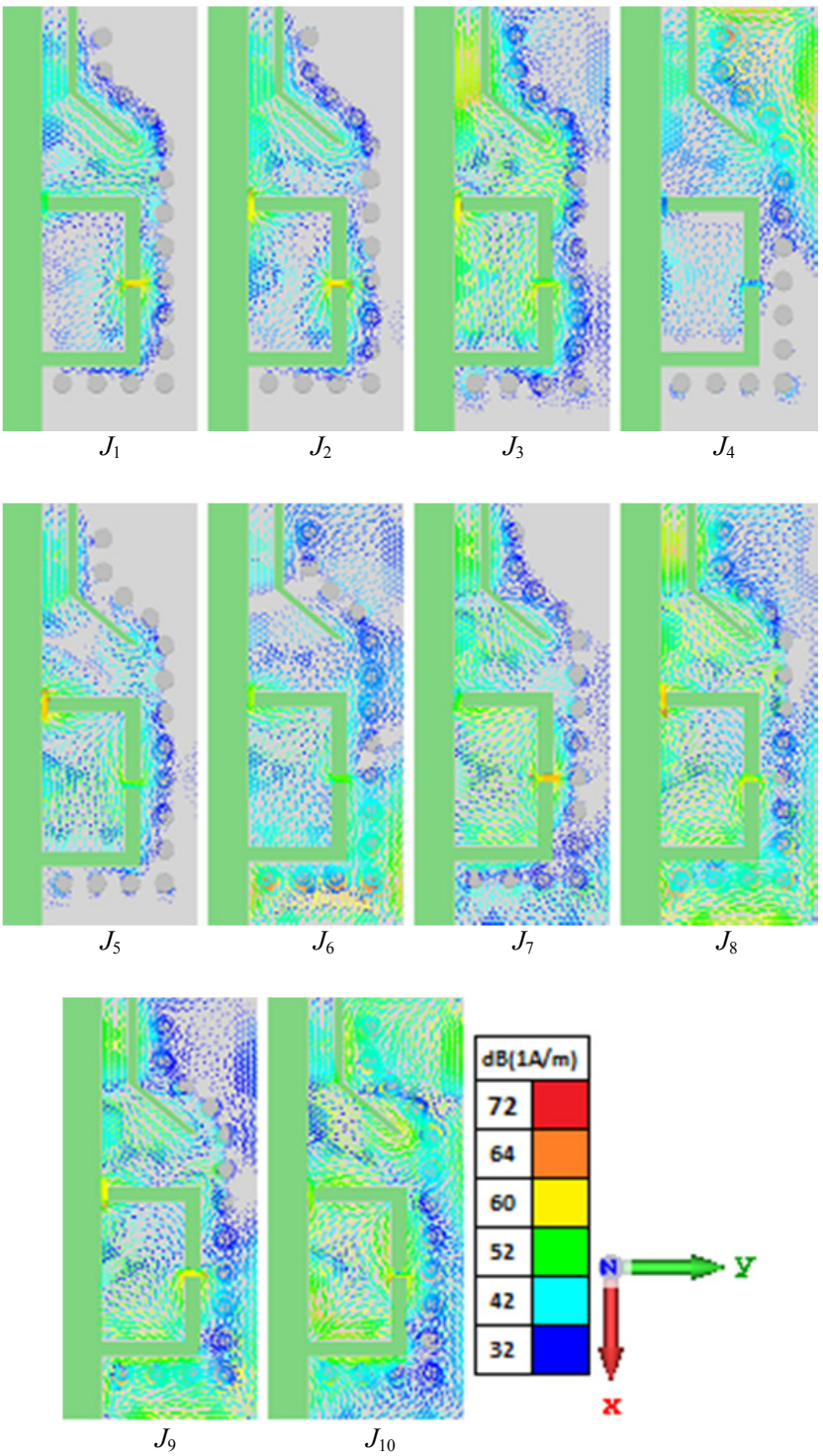

Fig. 3. CMA - surface currents.

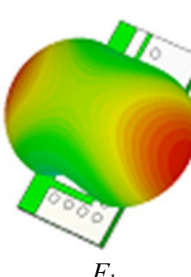

$F_{1}$
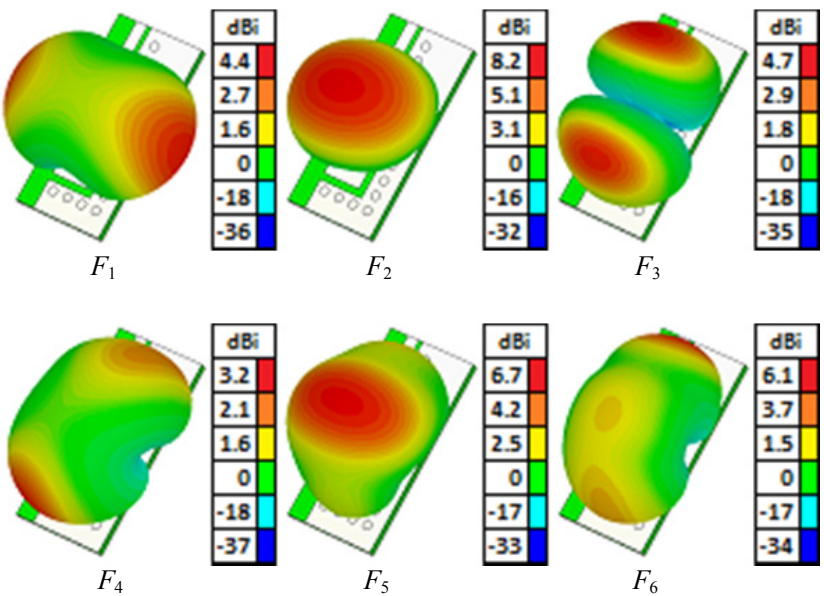
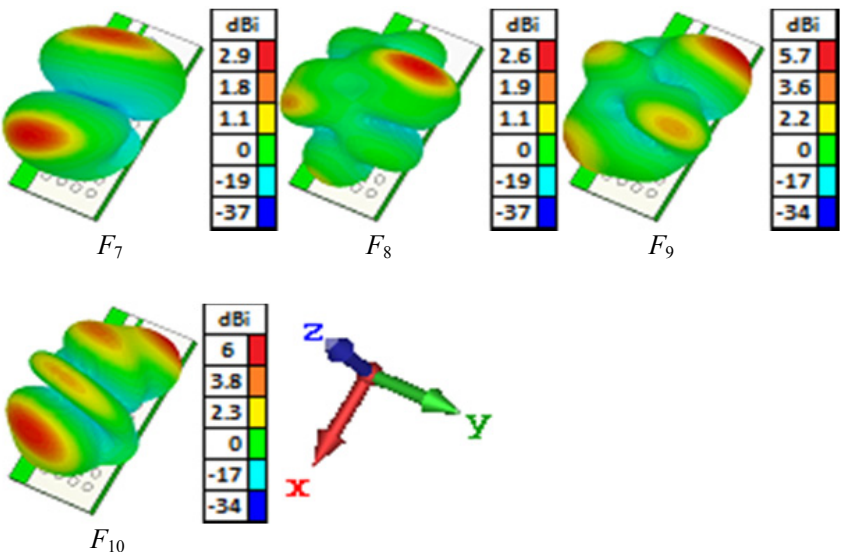

Fig. 4. CMA - radiations patterns.

The calculated radiation patterns are depicted in Fig. $4 . F_{n}$ represents the radiation patterns of mode $n$. Thanks to the distributions of modal surface currents $J_{2}$ and $J_{5}$, perpendicular radiation patterns $F_{2}$ and $F_{5}$ to the xy-plane are obtained.

\section{Design Guide}

The antenna can be easily retuned by varying the length $L_{\text {SLOT-X }}$ of the antenna in the X-direction and $L_{\text {SLOT-Y }}$ in the y-direction (Fig. 1). The distance $L_{\text {viax }}$ between the slot antenna and the shorting wall of the HMSIW heavily influences the operating frequency and reflection coefficient. The width of the slot $W_{\text {SLOT }}$ slightly influences the operating frequency and reflection coefficient of the antenna. Therefore, the design guide is created only from the viewpoint of the reflection coefficient. For creating the design guide, we used dielectric substrates mentioned in Tab. 2. It was created by tuning the antenna on dielectric substrates for the operating frequency $f_{\mathrm{o}}$ between $2 \mathrm{GHz}$ and $19 \mathrm{GHz}$ with a step of $1 \mathrm{GHz}$.

\begin{tabular}{|c|c|c|c|}
\hline Substrate & $\boldsymbol{\varepsilon}_{\mathrm{r}}[-]$ & $\tan (\boldsymbol{\delta})$ & $\boldsymbol{h}[\mathbf{m m}]$ \\
\hline FoamClad & 1.25 & 0.0035 & 1.86 \\
\hline CuClad 217 & 2.17 & 0.0009 & 0.79 \\
\hline Arlon25N & 3.38 & 0.0025 & 0.76 \\
\hline Arlon 600 & 6.15 & 0.003 & 1.58 \\
\hline
\end{tabular}

Tab. 2. Dielectric substrates used for design guide.

The first step of the design process began with choosing an appropriate dielectric substrate. Based on our experience, we recommended exploiting a dielectric substrate with lower relative permittivity, low circuit losses and suitable height. For that purpose, we chose the dielectric substrate CuClad 217.

The second step of the design process was determining the physical dimensions $L_{\text {SLOT-X, }} L_{\text {SLOT-Y, }} L_{\text {viaX }}, W_{\text {SLOT }}$ and width of the HMSIW. For this purpose, the physical dimensions can be easily deducted from Fig. 5(a-e). It was noted that the design guide did not support combining parameters during the design process. The curves mentioned in Fig. 5(a-e) are based on (1)-(4)

$$
L_{\text {slot-X }}=0.6 \lambda_{\mathrm{m}} k_{\mathrm{x}}(f), \quad[\mathrm{mm}, \mathrm{mm},-],
$$




\begin{tabular}{|c|c|c|c|c|c|c|}
\hline Substrate & $f_{\mathrm{o}}[\mathrm{GHz}]$ & $h[\mathrm{~mm}]$ & $k_{\mathrm{x}}(f)$ & $k_{\mathrm{y}}(f)$ & $k_{\mathrm{f}}(f)$ & $W_{\text {HMSIW }}[\mathrm{mm}]$ \\
\hline FoamClad & $2-19$ & 1.86 & $-0.00064 f_{\mathrm{o}}+1.0615$ & $-0.0019 f_{\mathrm{o}}+0.9418$ & $-0.0026 f_{\mathrm{o}}+0.414$ & $158.01 f_{\mathrm{o}}^{-1.085}$ \\
\hline CuClad 217 & $2-19$ & 0.79 & $-0.0025 f_{\mathrm{o}}+1.0093$ & $-0.002 f_{\mathrm{o}}+1.0908$ & $-0.0012 f_{\mathrm{o}}+0.3141$ & $82.991 f_{\mathrm{o}}^{-0.959}$ \\
\hline Arlon 25N & $2-39$ & 0.76 & $0.0012 f_{\mathrm{o}}+1.0285$ & $0.0016 f_{\mathrm{o}}+1.1477$ & $-3.10^{-5} f_{\mathrm{o}}+0.9935$ & $70.91 f_{\mathrm{o}}^{-0.959}$ \\
\hline Arlon 600 & $2-40$ & 1.58 & $0.0006 f_{\mathrm{o}}+1.0429$ & $0.0072 f_{\mathrm{o}}+1.0237$ & $0.0052 f_{\mathrm{o}}+0.7165$ & $63.09 f_{\mathrm{o}}^{-1.147}$ \\
\hline
\end{tabular}

Tab. 3. Correction factors $k_{\mathrm{x}}(f), k_{\mathrm{y}}(f)$ and $k_{\mathrm{f}}(f)$ and width $W_{\text {HMsIw. }}$

$$
\begin{aligned}
& L_{\text {slot-Y }}=0.35 \lambda_{\mathrm{m}} k_{\mathrm{y}}(f), \quad[\mathrm{mm}, \mathrm{mm},-], \\
& L_{\text {viaX }}=0.4 \lambda_{\mathrm{m}} k_{\mathrm{f}}(f), \quad[\mathrm{mm}, \mathrm{mm},-] \text {, } \\
& W_{\text {slot }}=0.045 \lambda_{\mathrm{m}}, \quad[\mathrm{mm}, \mathrm{mm},-]
\end{aligned}
$$

where $\lambda_{\mathrm{m}}$ is a wavelength of an operating frequency in a dielectric substrate and $k_{\mathrm{x}}(f), k_{\mathrm{y}}(f)$ and $k_{\mathrm{f}}(f)$ are correction factors. The correction factors are expressed numerically in Tab. 3.

The final step of the design procedure ends with fine tuning of the antenna at the desirable frequency with the help of a local optimization procedure, e.g., Trust Region Framework or Nedler Mead Simplex Algorithm (CST MWS).

If the design process takes place on a different dielectric substrate than mentioned in Tab. 2, the following simplified design rules can be used in order to tune the designed antenna at the desired frequency. The length $L_{\text {SLOT-X }}$ and $L_{\text {SLOT-Y }}$ should be $0.6 \lambda_{\mathrm{m}}$ and $0.35 \lambda_{\mathrm{m}}$, respectively. The $\lambda_{\mathrm{m}}$ is the wavelength in the dielectric substrate at the design frequency. Obviously, the width of the slot $W_{\text {SLOT }}$ depends on the portion of $\lambda_{\mathrm{m}}$, e.g., $\lambda_{\mathrm{m}} / 45$. The distance $L_{\mathrm{via}}$ between

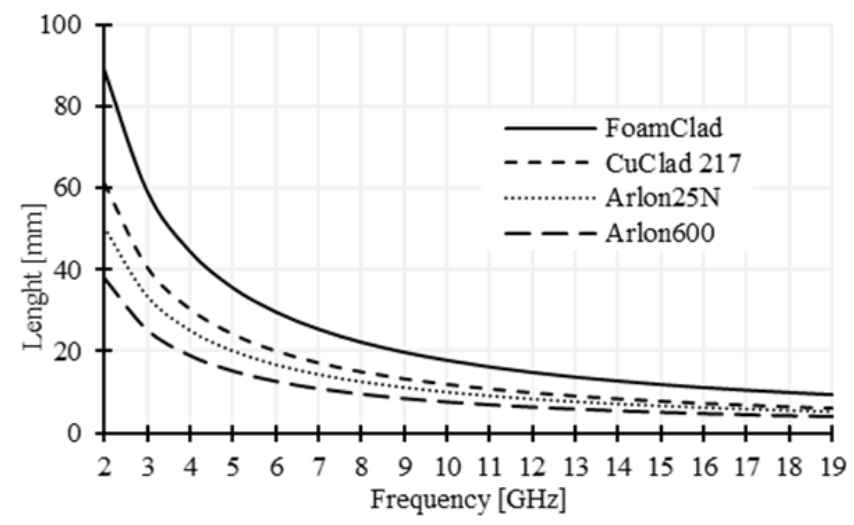

(a)

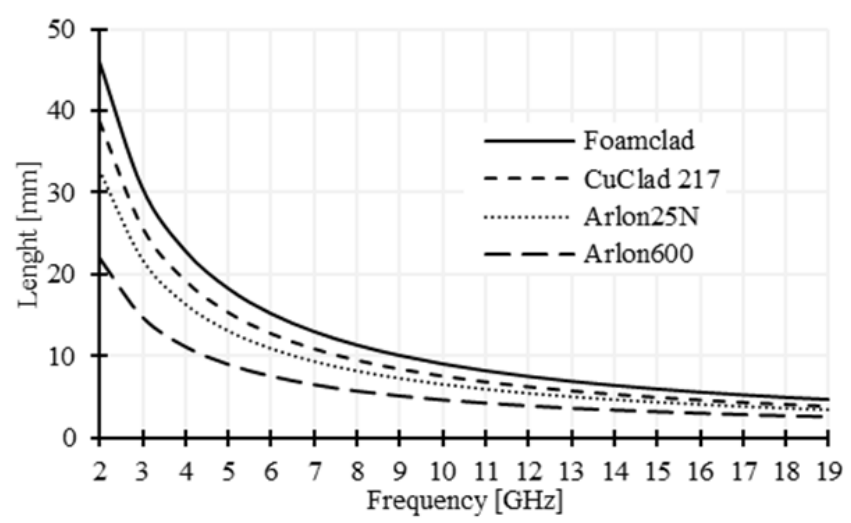

(b)

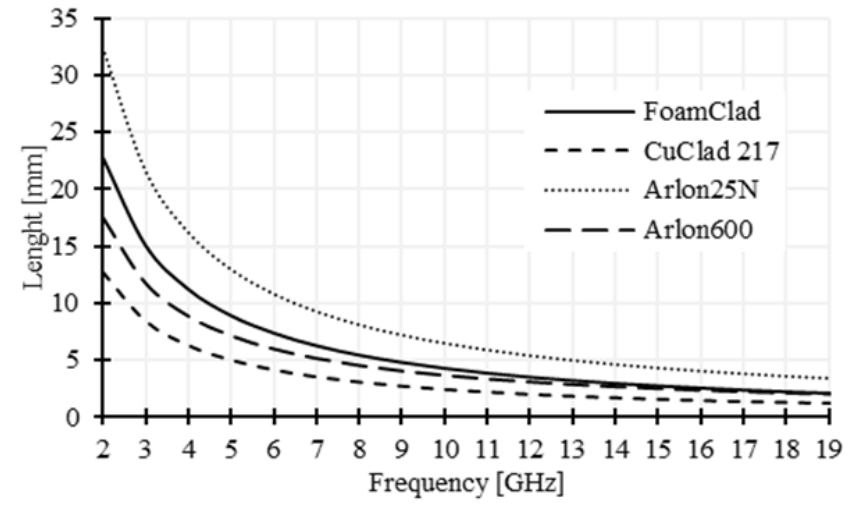

(c)

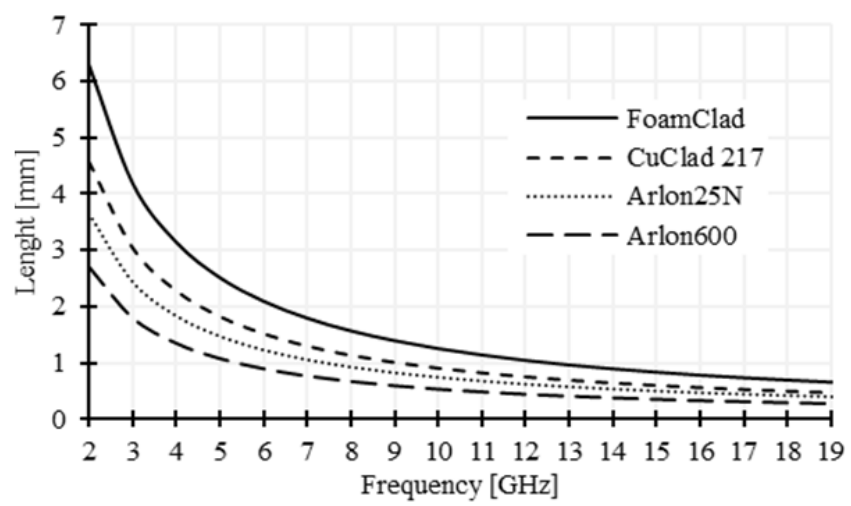

(d)

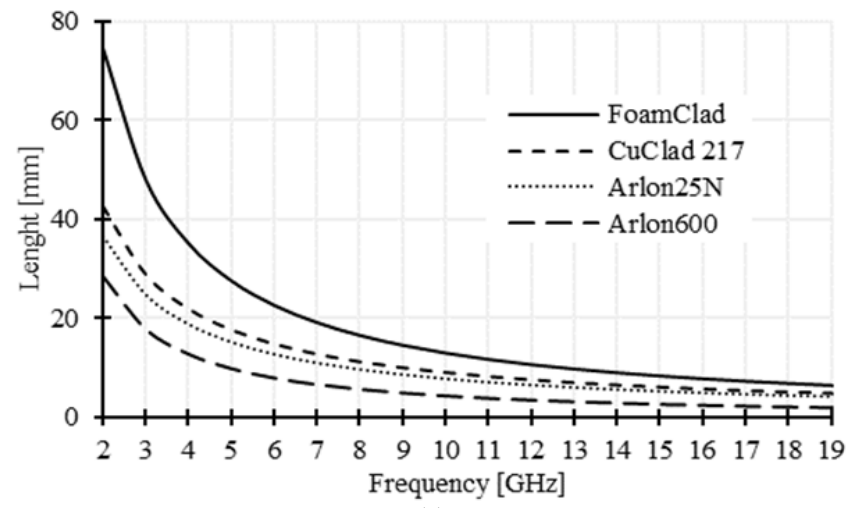

(e)

Fig. 5. Physical dimension of (a) $L_{\mathrm{SLOT}-\mathrm{X}}$, (b) $L_{\mathrm{SLOT}-\mathrm{Y}}$, (c) $L_{\mathrm{viaX}}$, (d) $W_{\text {SLOT }}$, (e) HMSIW.

slot antenna and shorting wall of HMSIW should be $0.3 \lambda_{\mathrm{m}}$. The width of the HMSIW $W_{\text {HMSIW }}$ can be determined by the help of (8)-(13), published in [21]. Two conditions of the design of the HMSIW have to be met: the HMSIW operates in the fundamental mode $\mathrm{TE}_{0.5,0}$ and the operating frequency of the antenna is approximately 1.5 times higher than the cut-off frequency of the fundamental mode $\mathrm{TE}_{0.5,0}$. However, for the finalization of the design, a local optimization procedure should be used. 


\subsection{Experimental Verification of the Design Guide}

To verify the proposed antenna design guide experimentally, several antennas have been designed by the proposed design guide at operating frequency mentioned in Tab. 4. The operating frequencies are chosen randomly from the frequency pool $f_{\mathrm{o}}$ between $2 \mathrm{GHz}$ and $19 \mathrm{GHz}$ using a standard coaxial connector for the feeding of the antennas. The antennas are designed using the time domain solver from CST MWS. The optimization technique called Trust Region Framework is used to optimize the antenna for a desired operating frequency band. After finishing optimization, the antennas were fabricated by a low-cost etching PCB process. The estimated precision is in the range of tens of micrometers. The printed board was drilled with Bungard CCD/ATC (Computer Controlled Drilling machine with Automatic Tool Change). The diameter of the drilled vias is $1.4 \mathrm{~mm}$ and the position accuracy is $20 \mathrm{ppm}$. Fabricated samples of the antennas are depicted in Fig. 11.

The reflection coefficient of the fabricated antennas was measured in a laboratory environment by a vector network analyzer. The simulated and measured reflection coefficients of the designed antennas are depicted in Fig. 6(a)-(e). The dashed line represents the design of the antenna by the design guide. The solid line represents optimization of the antennas by the local optimization process. The dark solid line represents measurements of the antennas. The measured results (b) and (c) are in good agreement compared to the simulated ones. The measured results (a) and (d) are slightly different in comparison to the simulated ones. In case (a), the dielectric substrate FoamClad is easily bendable, thus the measured minimum of reflection coefficient is slightly shifted to the lower frequencies. In case (d), based on the simulated and the measured results, the antenna is not suitable for operation on a dielectric substrate with a higher relative permittivity. The measured results do not correspond to the simulated results. In case (b) and (c), the measured results might be shifted in point of view of the manufacturing tolerance (see Sec. 4.2).

The normalized radiation patterns in two orthogonal cutting planes are depicted in Figs. 7-10. The measurement was done in anechoic chamber for the Theta range from $-90^{\circ}$ to $90^{\circ}$. The measured patterns might be slightly shifted due to parasitic radiation of the GCPW and manufacturing tolerance. A comparison between measured results of the experimental verification of the DG with the results of previously reported HMSIW based antennas [3-18] is presented in Tab. 5. Based on measured results, the U-slot HMSIW antennas achieve better gains in comparison to the other antennas. The width of impedance bandwidth and the size of the antennas are at average level in comparison to the other antennas.

\begin{tabular}{|c|c|}
\hline Substrate & $\boldsymbol{f}_{\mathbf{0}}[\mathbf{G H z}]$ \\
\hline FoamClad & 10 \\
\hline CuClad 217 & 12 \\
\hline Arlon25N & 8 \\
\hline Arlon 600 & 7 \\
\hline
\end{tabular}

Tab. 4. Design of the antenna at the specific frequency.

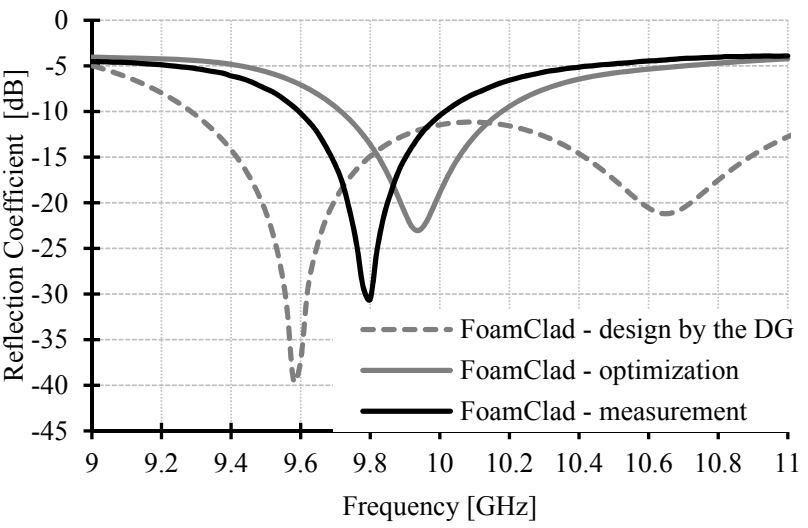

(a)

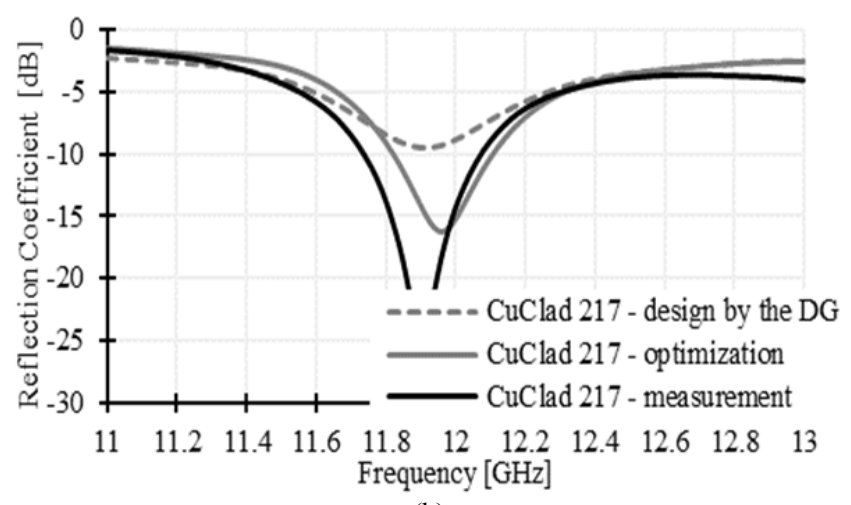

(b)

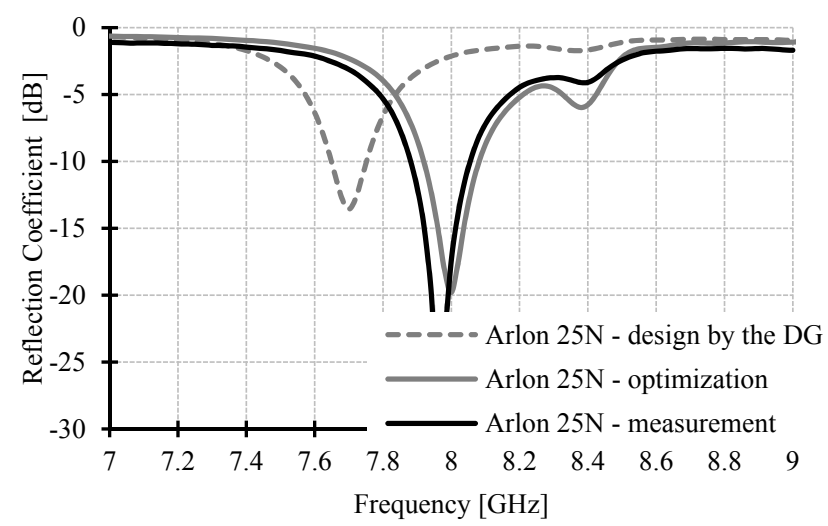

(c)

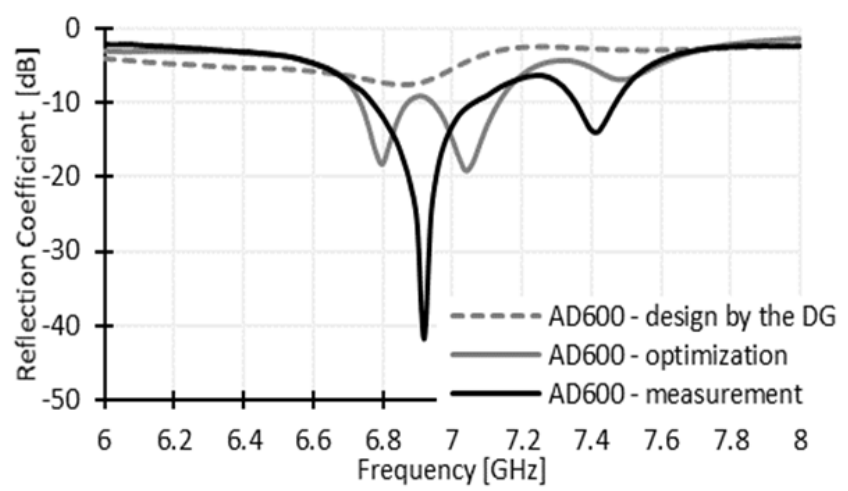

(d)

Fig. 6. Experimental verification of the design guide: Reflection coefficient: (a) FoamClad, (b) CuClad 217, (c) Arlon25N, (d) Arlon 600. 


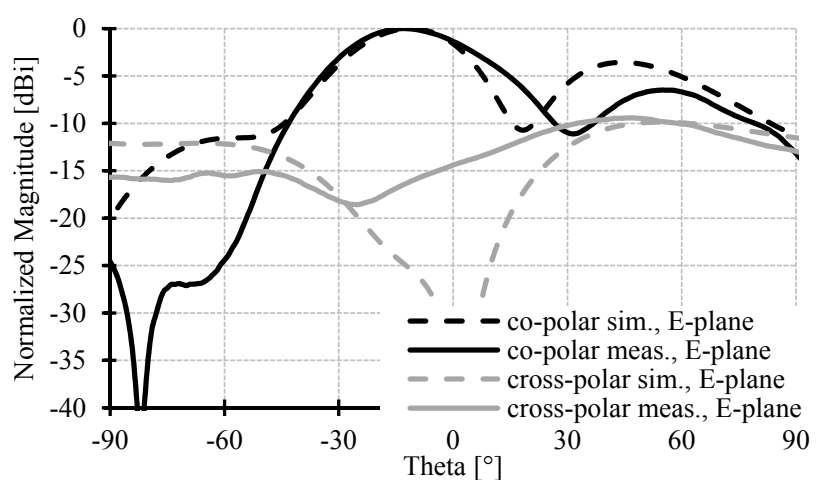

(a)

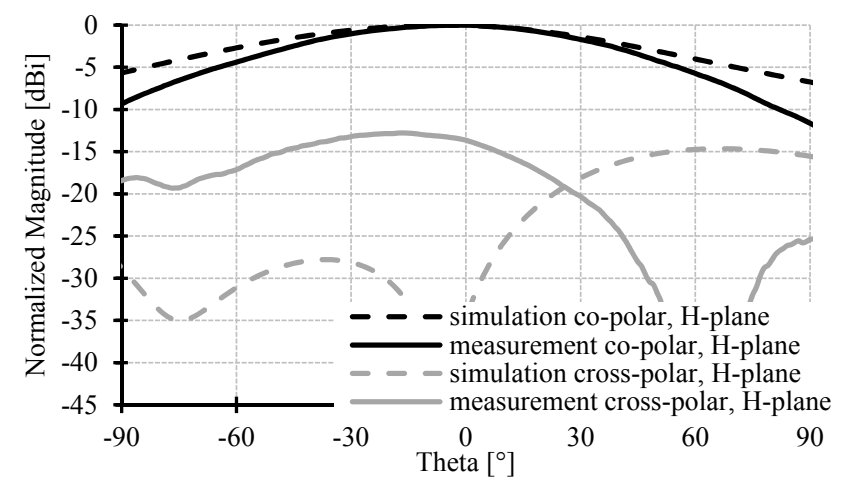

(b)

Fig. 7. Experimental verification of the design guide: Normalized magnitude measured at $10 \mathrm{GHz}$, substrate FoamClad: (a) E-plane, (b) H-plane.

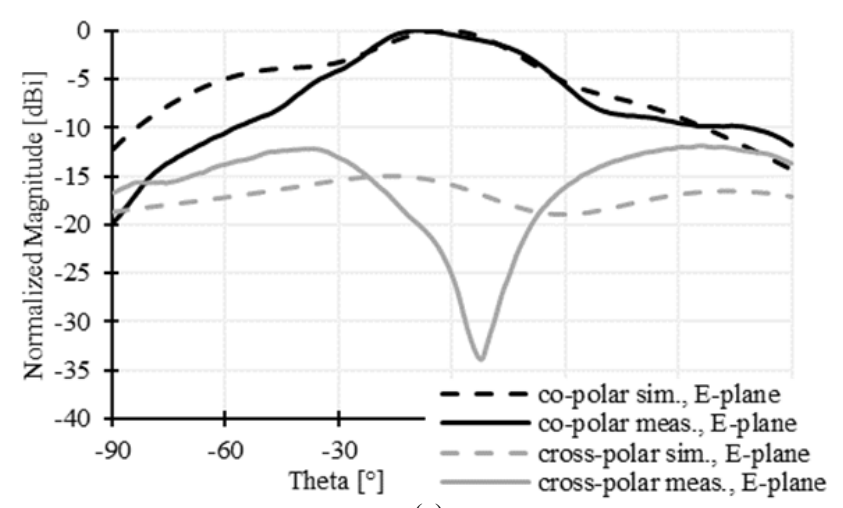

(a)

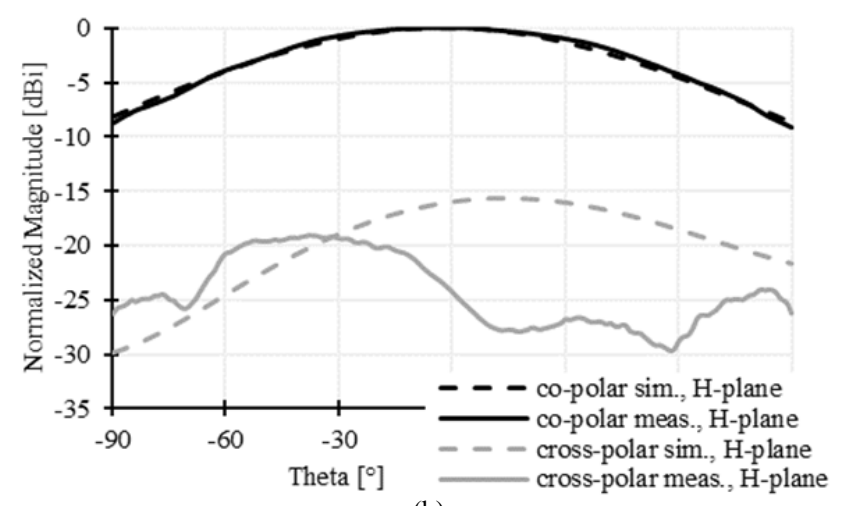

(b)

Fig. 8. Experimental verification of the design guide: Normalized magnitude measured at $12 \mathrm{GHz}$, substrate CuClad 217: (a) E-plane, (b) H-plane.

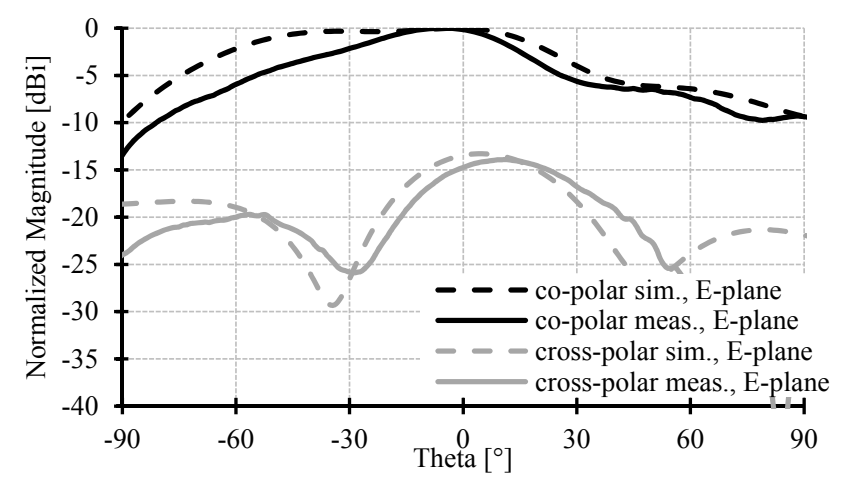

(a)

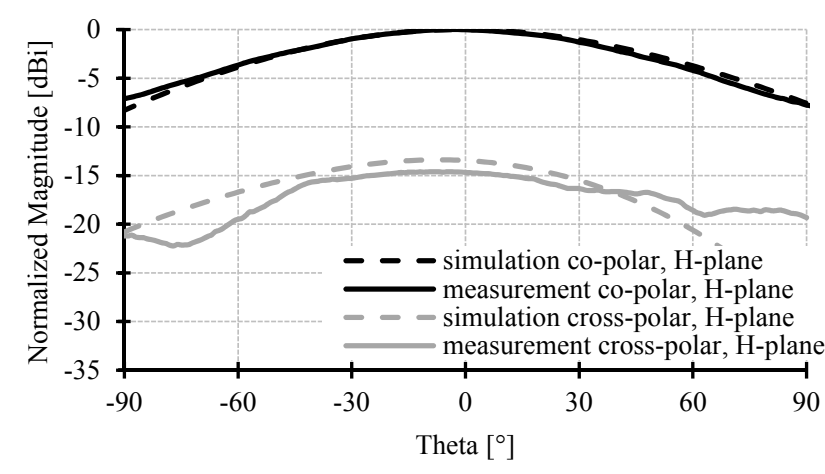

(b)

Fig. 9. Experimental verification of the design guide: Normalized magnitude measured at $8 \mathrm{GHz}$, substrate Arlon25N: (a) E-plane, (b) H-plane.

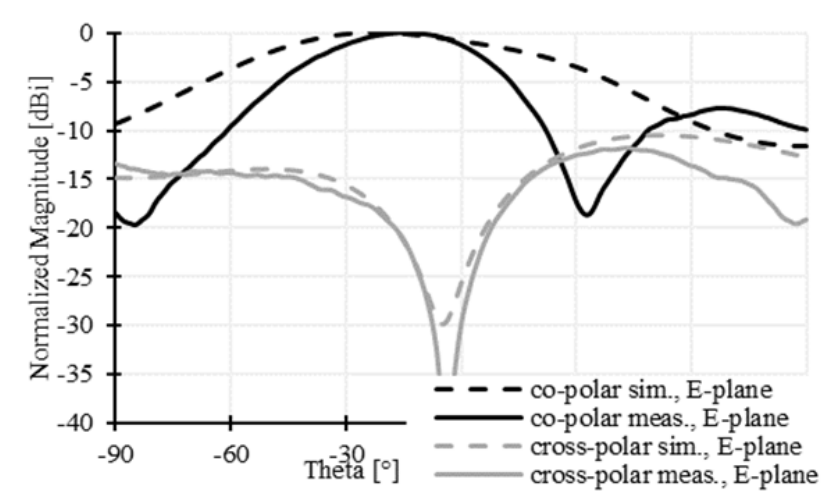

(a)

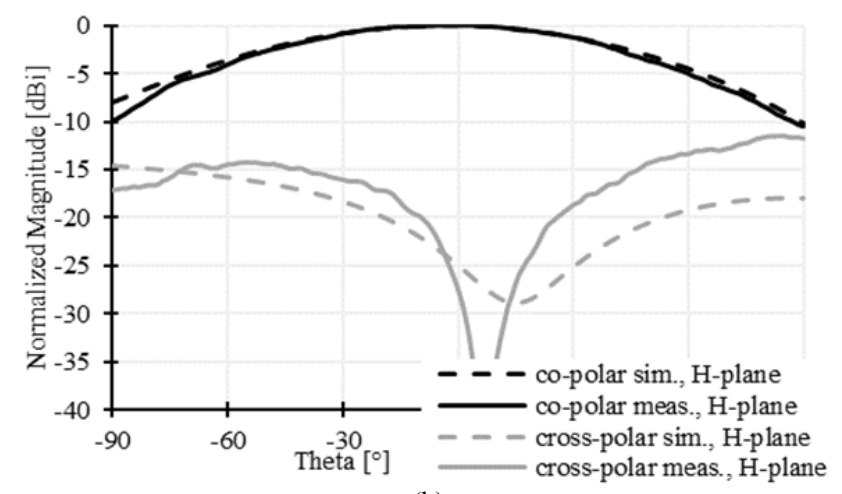

(b)

Fig. 10. Experimental verification of the design guide: Normalized magnitude measured at $7 \mathrm{GHz}$, substrate Arlon 600: (a) E-plane, (b) H-plane. 


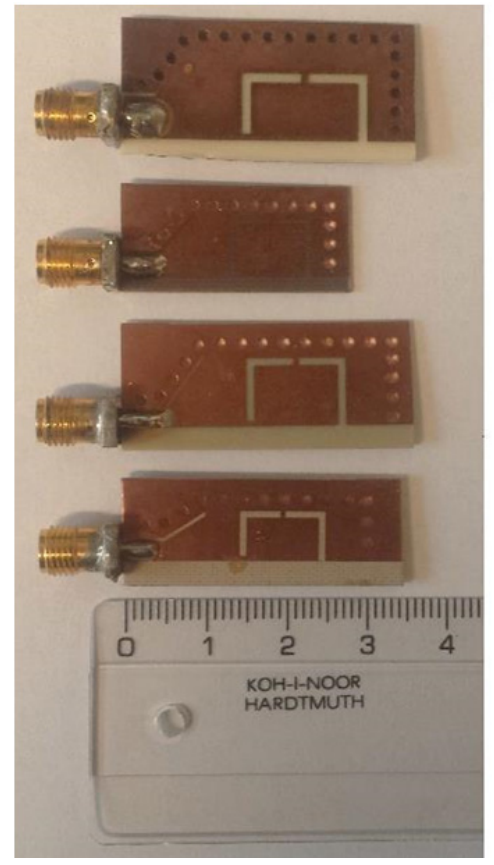

a)

b)

c)

d)

Fig. 11. Manufactured sample of the antennas: (a) FoamClad, (b) CuClad 217, (c) Arlon 25N, (d) Arlon 600.

\begin{tabular}{|c|c|c|c|c|c|c|}
\hline & Substrate & $\begin{array}{c}\text { Operating } \\
\text { frequency } \\
\text { [GHz] }\end{array}$ & \begin{tabular}{|c|}
$S 11<$ \\
$-10 \mathrm{~dB}$ \\
{$[\%]$} \\
\end{tabular} & $\begin{array}{l}\text { Gain } \\
{[\mathrm{dBi}]}\end{array}$ & Antenna size & $\mid \begin{array}{l}\text { Substrate } \\
\text { thickness }\end{array}$ \\
\hline \multirow{4}{*}{ 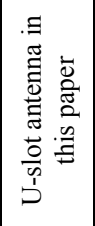 } & FoamClad & 10 & 6 & 7.4 & $1.18 \lambda_{0} \times 0.56 \lambda_{0}$ & $0.06 \lambda_{0}$ \\
\hline & \begin{tabular}{|c|} 
CuClad21 \\
7 \\
\end{tabular} & 12 & 2.9 & 6.7 & $1.09 \lambda_{0} \times 0.51 \lambda_{0}$ & $0.03 \lambda_{0}$ \\
\hline & Arlon25N & 8 & 1.7 & 5.6 & $0.93 \lambda_{0} \times 0.41 \lambda_{0}$ & $0.02 \lambda_{0}$ \\
\hline & Arlon 600 & 7 & 2 & 5.7 & $0.81 \lambda_{0} \times 0.28 \lambda_{0}$ & $0.04 \lambda_{0}$ \\
\hline \multicolumn{2}{|c|}{ Slot antenna [3] } & 4.9 & 1.1 & - & $0.31 \lambda_{0} \times 2.48 \lambda_{0}$ & $0.03 \lambda_{0}$ \\
\hline \multicolumn{2}{|c|}{ E slot [4] } & 7.6 & 1 & 4.6 & - & $001 \lambda$ \\
\hline \multicolumn{2}{|c|}{ Z-slot [5] } & 15.5 & 3.5 & 5.6 & $0.12 \lambda_{0} \times 1.55 \lambda_{0}$ & $008 \lambda$ \\
\hline \multicolumn{2}{|c|}{ T-slot [6] } & 4.8 & 1 & $2.8 \mathrm{sim}$ & $0.96 \lambda_{0} \times 0.96 \lambda_{0}$ & $0.01 \lambda_{0}$ \\
\hline \multicolumn{2}{|c|}{ Cavity-backed [7] } & 8.5 & 4.9 & 6.7 & $0.48 \lambda_{0} \times 1.0 \lambda_{0}$ & $0.02 \lambda_{0}$ \\
\hline \multicolumn{2}{|c|}{$\begin{array}{c}\text { Dual band U-slot } \\
{[8]}\end{array}$} & $5.8 / 7$ & $2.2 / 2.4$ & $5.9 / 5.1$ & $1.09 \lambda_{0} \times 0.28 \lambda_{0}$ & $0.02 \lambda_{0}$ \\
\hline \multicolumn{2}{|c|}{$\begin{array}{c}\text { Cavity-backed slot } \\
{[9]}\end{array}$} & 2.4 & 1.7 & 4.1 & $0.23 \lambda_{0} \times 0.35 \lambda_{0}$ & $0.01 \lambda_{0}$ \\
\hline \multicolumn{2}{|c|}{$\begin{array}{c}\text { Triangular antenna } \\
{[10]}\end{array}$} & 5.3 & 0.9 & 5.6 & $0.7 \lambda_{0} \times 0.7 \lambda_{0}$ & $0.01 \lambda_{0}$ \\
\hline \multicolumn{2}{|c|}{$\begin{array}{c}\text { Semi-circular } \\
\text { antenna [10] }\end{array}$} & $5.2 \mathrm{sim}$ & $\begin{array}{l}1.1 \\
\text { sim } \\
\end{array}$ & $5.3 \mathrm{sim}$ & $1.04 \lambda_{0} \times 1.04 \lambda_{0}$ & $0.01 \lambda_{0}$ \\
\hline \multicolumn{2}{|c|}{$\begin{array}{c}\text { Semi-hexagonal } \\
\text { antenna [11] }\end{array}$} & 5.6 & 1.2 & 5.3 & $1.12 \lambda_{0} \times 1.12 \lambda_{0}$ & $0.02 \lambda_{0}$ \\
\hline \multicolumn{2}{|c|}{$\begin{array}{c}\text { Triangular slot } \\
{[12]}\end{array}$} & 4.5 & 0.2 & 2.3 & $0.9 \lambda_{0} \times 0.9 \lambda_{0}$ & $0.01 \lambda_{0}$ \\
\hline \multicolumn{2}{|c|}{$\begin{array}{c}\text { Semi-circular slot } \\
{[13]}\end{array}$} & $4.8 \mathrm{sim}$ & $\begin{array}{r}0.9 \\
\text { sim } \\
\end{array}$ & $4.9 \mathrm{sim}$ & $0.96 \lambda_{0} \times 0.96 \lambda_{0}$ & $0.01 \lambda_{0}$ \\
\hline \multicolumn{2}{|c|}{$\begin{array}{c}\text { Semi-hexagonal } \\
\text { slot [11] }\end{array}$} & 4.9 & 0.8 & 3.4 & $0.98 \lambda_{0} \times 0.98 \lambda_{0}$ & $0.01 \lambda_{0}$ \\
\hline \multicolumn{2}{|c|}{$\begin{array}{c}\text { Low-profile patch } \\
{[16]}\end{array}$} & 8.1 & 10 & 7.5 & $0.63 \lambda_{0} \times 0.58 \lambda_{0}$ & $0.02 \lambda_{0}$ \\
\hline \multicolumn{2}{|c|}{$\begin{array}{c}\text { Aperture-coupled } \\
\text { DRA [17] }\end{array}$} & 60 & 24 & 5.5 & $0.44 \lambda_{0} \times 1.78 \lambda_{0}$ & $0.03 \lambda_{0}$ \\
\hline \multicolumn{2}{|c|}{ Horn antenna [18] } & 27.3 & 1.2 & 5.9 & $1.7 \lambda_{0} \times 1.7 \lambda_{0}$ & $0.18 \lambda_{0}$ \\
\hline
\end{tabular}

Tab. 5. Measured results.

\subsection{Parametric Study}

The measured results are a bit different compared to simulated ones, especially the cross-polarizations of the antenna realized of the FoamClad and Cuclad217 dielectric substrate. To fully understand to the differences, a parametric analysis is carried out and the results are depicted in Fig. 12 and 13. The analysis was carried out by varying the physical length of the antenna slot (Fig. 1) in the X-direction $\left(L_{\text {slot-x }}=15.56 \mathrm{~mm}\right.$, step $\left.0.15 \mathrm{~mm}\right)$ and the y-direction $\left(L_{\text {slot-y }}=8.07 \mathrm{~mm}\right.$, step $\left.0.08 \mathrm{~mm}\right)$. The studied antenna is designed for the FoamClad dielectric substrate and the operating frequency of $10 \mathrm{GHz}$. Obviously, the length of the slot in the x-direction $L_{\text {slot-x }}$ heavily influences operating frequency, impedance matching and cross-polarization of the antenna (Fig. 12). The length of the slot in the y-direction $L_{\text {slot-y }}$ heavily influences mainly the impedance matching and cross-polarization of the antenna (Fig. 13). Based on the parametric analysis, the antenna is very sensitive to changes of physical dimensions. The observed measured inaccuracies in Sec. 4.1 might be caused by the inaccurate manufacture process (inaccurate printing of PCB, drilling and insufficient plating of holes in $\mathrm{PCB}$ and inaccurate cutting of the PCB) or inaccurate preparation of the antenna for measurement (inaccurate soldering of the coaxial connector to the PCB, inaccurate mounting of the antenna in the antenna chamber) or any combination of these mentioned inaccuracies.

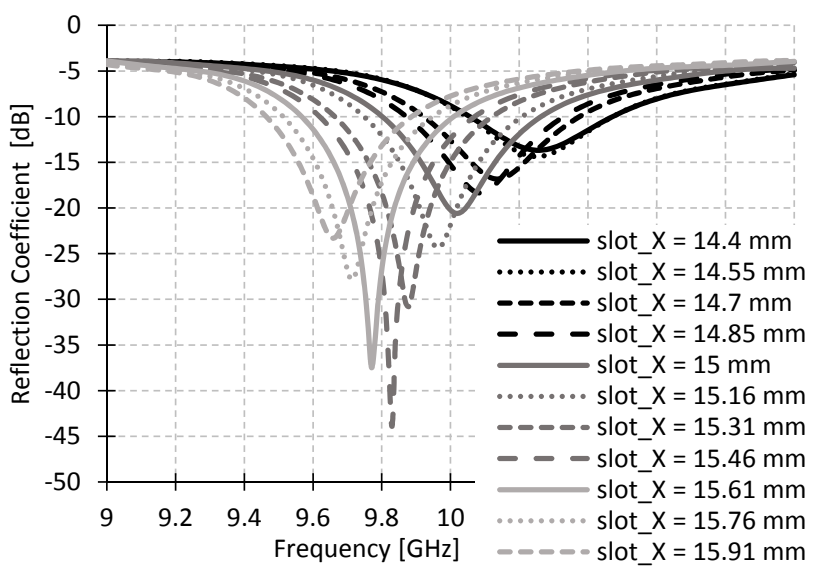

(a)

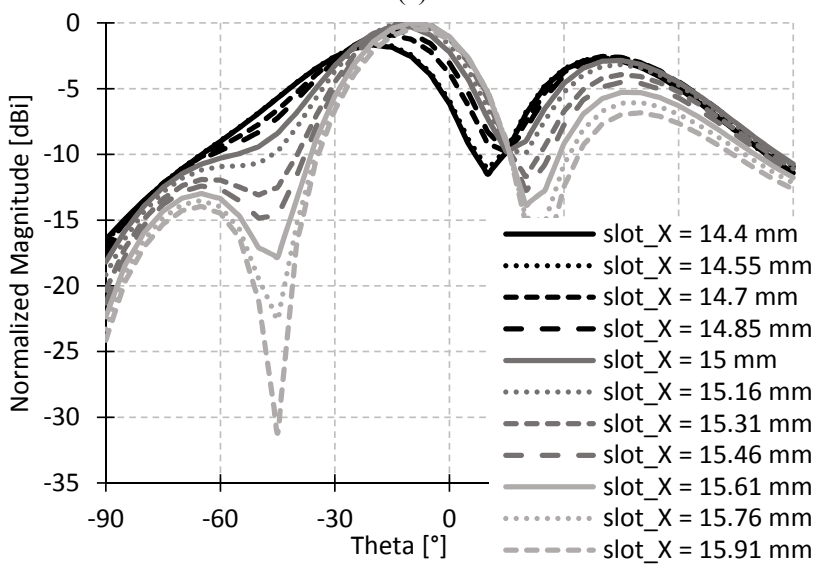

(b) 


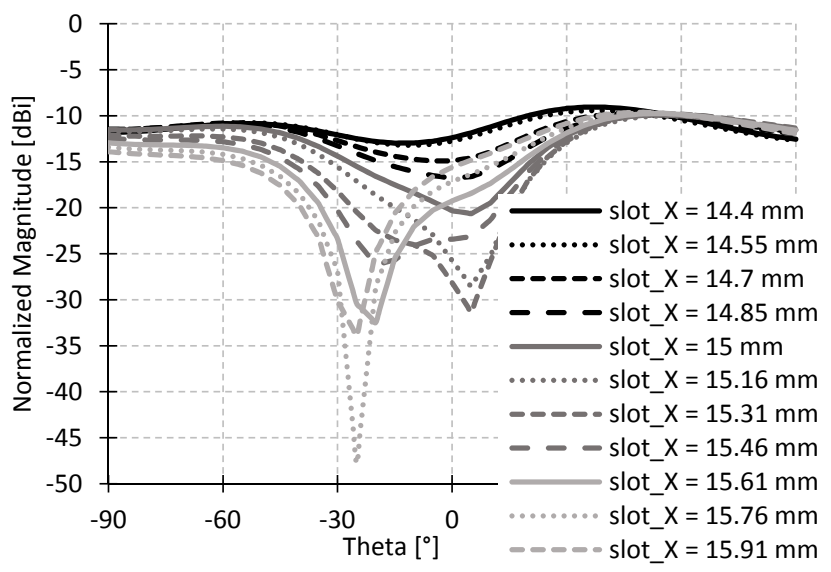

(c)

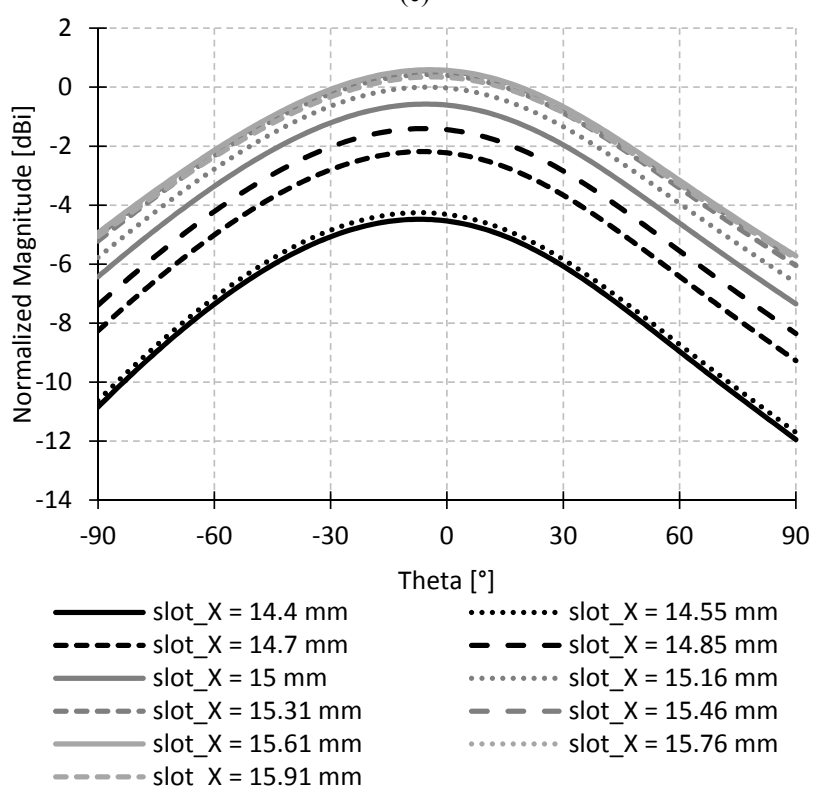

(d)

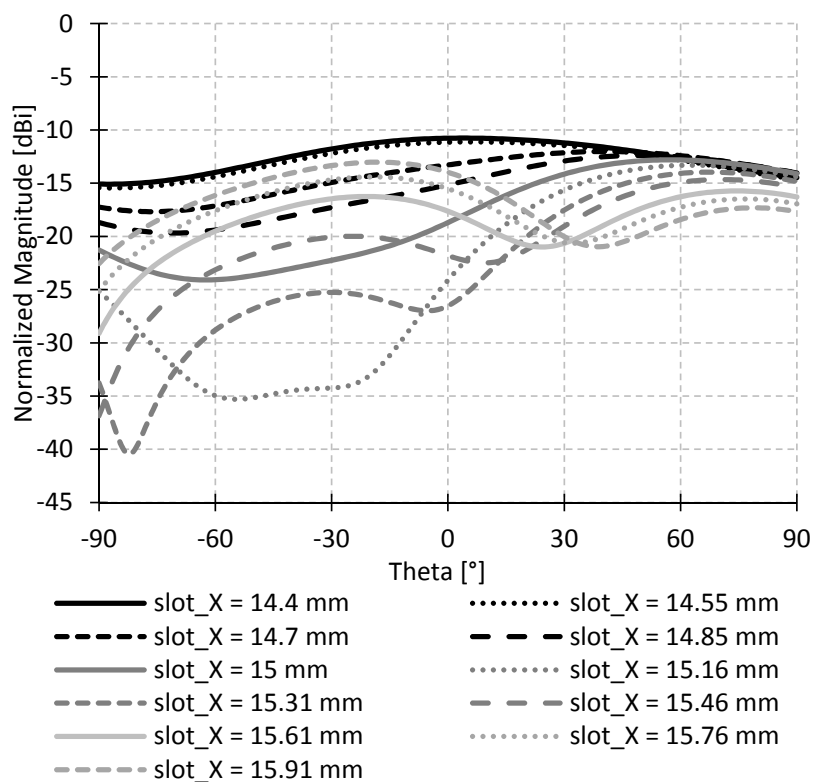

(e)

Fig. 12. Influence of slot length in $\mathrm{x}$-direction $L_{\text {slot-x }}$ on (a) reflection coefficient, (b) co-polarization in E-plane, (c) cross-polarization in E-plane, (d) co-polarization in $\mathrm{H}$-plane and (e) cross-polarization in H-plane.

\section{Conclusion}

In this paper, a characteristic mode analysis and design guide of the HMSIW linearly polarized U-slot antenna has been introduced. Based on the results of the CMA, the antenna might work as a multi-mode antenna with wider impedance bandwidth at a higher frequency band. Thus, there might be new possibilities for increasing performance of the antenna and exploiting the antenna for suitable applications.

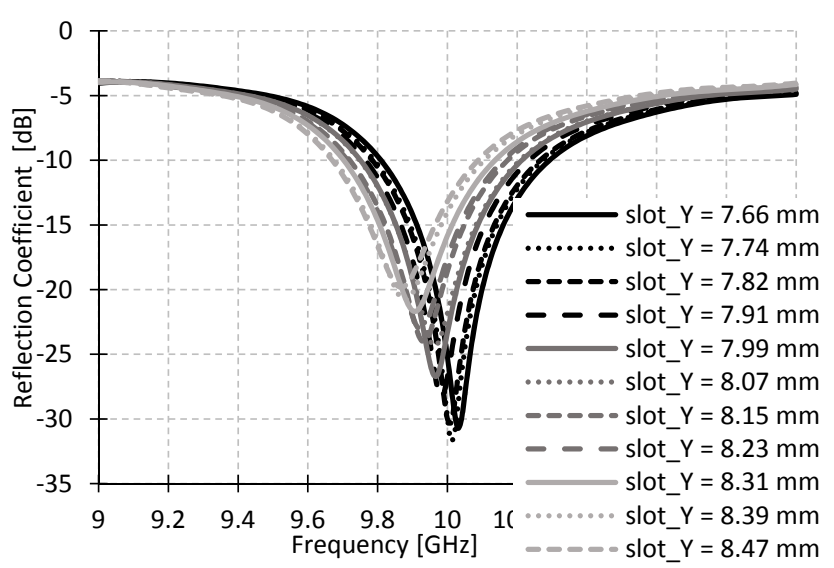

(a)

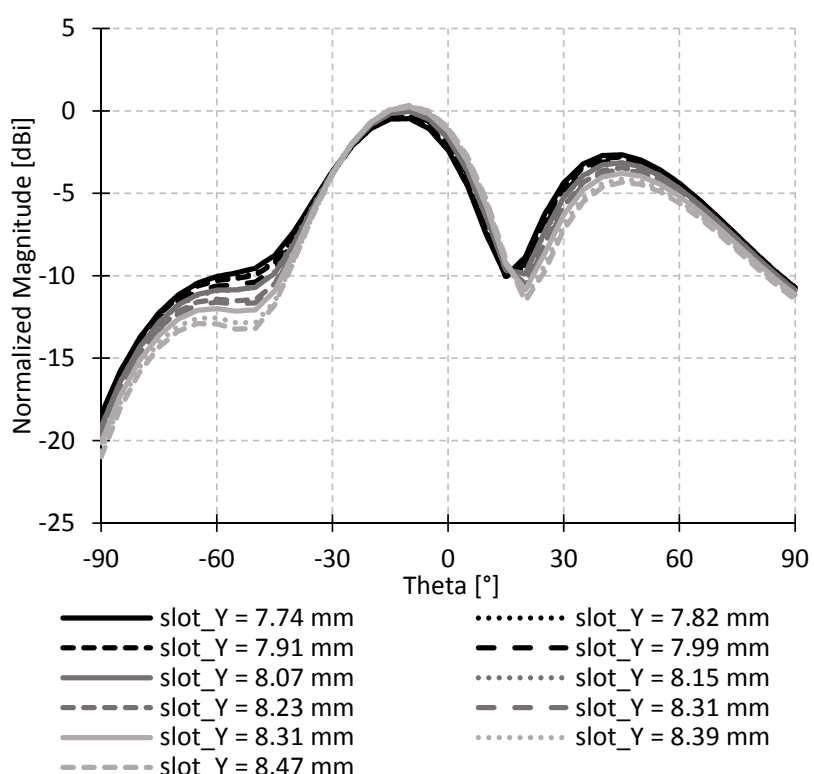

(b)

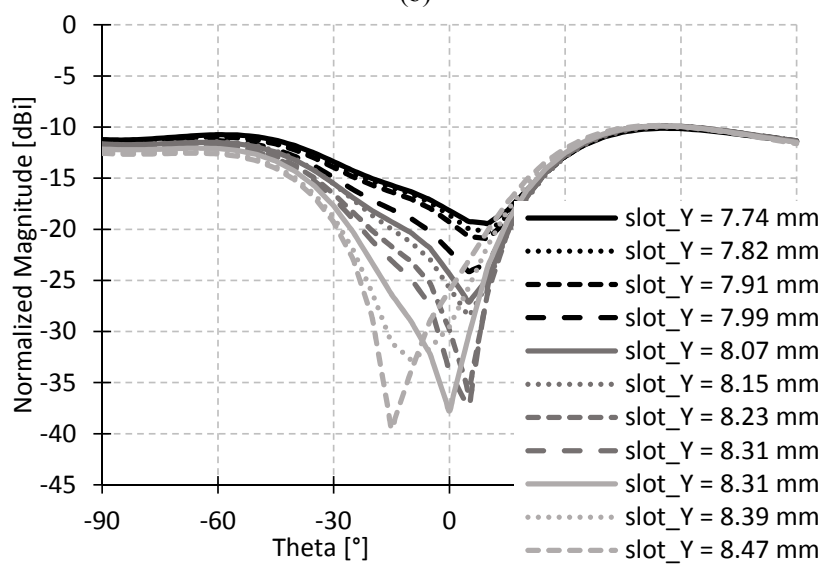

(c) 


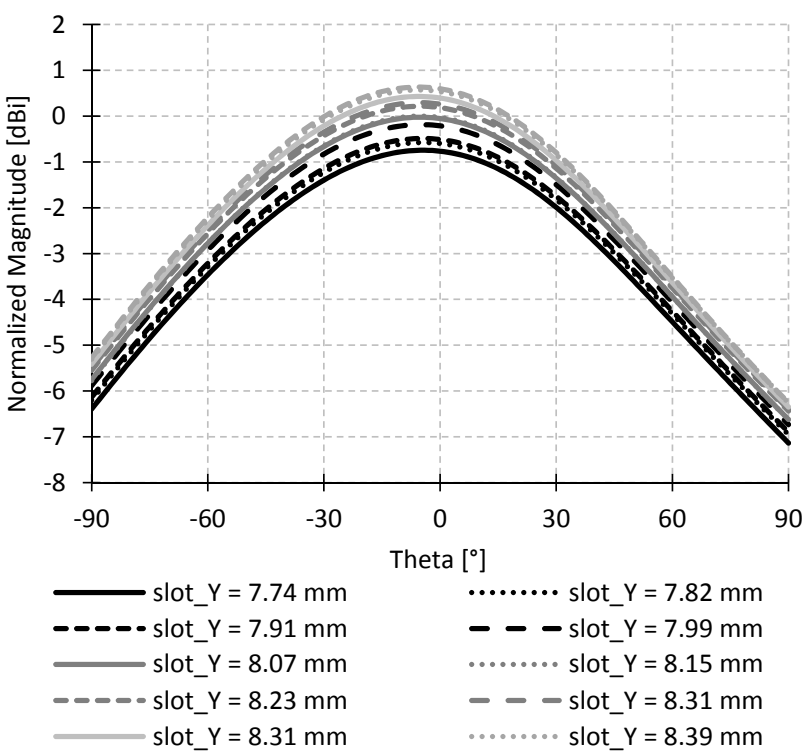

(d)

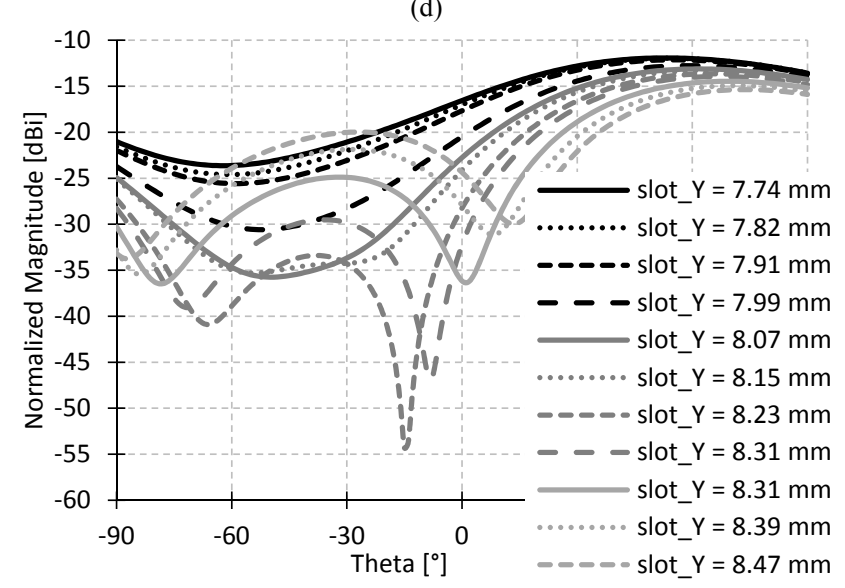

(e)

Fig. 13. Influence of slot length in y-direction $L_{\text {slot-y }}$ on: (a) reflection coefficient, (b) co-polarization in E-plane, (c) cross-polarization in E-plane, (d) co-polarization in H-plane and (e) cross-polarization in H-plane.

\section{Acknowledgments}

Research described in this contribution was supported by the Czech Ministry of Education within the framework of the National Sustainability Program under grant LO1401 and by the Internal Grant Agency of Brno University of Technology, project no. FEKT-S-20-6526. For research, infrastructure of the SIX Center was used.

\section{Reference}

[1] UCHIMURA, H., TAKENOSHITA, T., FUJII, M. Development of a "laminated waveguide". IEEE Transactions on Microwave Theory and Techniques, 2014, vol. 46, p. 2438-2443. DOI: $10.1109 / 22.739232$

[2] HONG, W., LIU, B., WANG, Y., et al. Half mode substrate integrated waveguide: A new guided wave structure for microwave and millimeter wave application. In Joint 31st
International Conference on Infrared Millimeter Waves and 14th International Conference on Terahertz Electronics. Shangai (China), 2006, p. 219-219. DOI: 10.1109/ICIMW.2006.368427

[3] WU, L., SANZ IZQUIERDO, B., YOUNG, P. R. Half mode substrate integrated waveguide slot antenna. In IEEE Antennas and Propagation Society International Symposium. Charleston (USA), 2009, p. 1-4. DOI: $10.1109 /$ APS.2009.5171677

[4] LIU, S., XU, F., WU, K. A compact E-shaped half-mode substrate integrated waveguide semi-circular antenna. In IEEE MTT-S International Wireless Symposium (IWS). Chengdu (China), 2018, p. 1-3. DOI: 10.1109/IEEE-IWS.2018.8400897

[5] RANA, B., PARUI, S. K. Half-mode substrate integrated waveguide fed compact slot antenna. In IEEE Applied Electromagnetics Conference (AEMC). Bhubaneswar (India), 2013, p. 1-2. DOI: 10.1109/AEMC.2013.7044912

[6] BANERJEe, S., CHATTERJEE, S., MAZUMDAR, S. D., et al. A compact half-mode SIW semi-hexagonal antenna with T-shaped slot. In 2017 2nd International Conference for Convergence in Technology (I2CT). Mumbai (India), 2017, p. 733-737. DOI: 10.1109/I2CT.2017.8226225

[7] RAZAVI, S. A., NESHATI, M. H. Development of a linearly polarized cavity-backed antenna using HMSIW technique. IEEE Antennas and Wireless Propagation Letters, 2014, vol. 11, p. 1307-1310. DOI: 10.1109/LAWP.2012.2227231

[8] JIANG, S., WANG, Z., TANG, H. Design of dual band SIW and HMSIW cavity backed U-shaped slot antennas. In 2018 10th International Conference on Communication Software and Networks (ICCSN 2018). Chengdu (China), 2018, p. 452-455. DOI: 10.1109/ICCSN.2018.8488284

[9] ASTUTI, D. W., RAHARDJO, E. T. Size reduction of cavity backed slot antenna using half mode substrate integrated waveguide structure. In 2018 4th International Conference on Nano Electronics Research and Education (ICNERE). Hamamatsu (Japan), 2018, p. 1-4. DOI: 10.1109/ICNERE.2018.8642564

[10] BANERJEE, S., MOHANTY, T., DAS, S. Slot-loaded compact HMSIW triangular antenna. In 2016 International Conference on Microelectronics, Computing and Communications (MicroCom). Durgapur (India), 2016, p. 1-4. DOI: 10.1109/MicroCom.2016.7522502

[11] BANERJEE, S., TWINKLE, M. A miniaturized half-mode SIW based semi-circular antenna with arc-shaped slot. In 2017 2nd International Conference for Convergence in Technology (I2CT). Mumbai (India), 2017, p. 128-131. DOI: 10.1109/I2CT.2017.8226107

[12] BANERJEE, S., DEBNATH, M., BOSE, S., et al. Compact HMSIW semi-hexagonal antennas with rectangular slot. In 2019 International Conference on Opto-Electronics and Applied Optics (Optronix). Kolkata (India), 2019, p. 1-6. DOI: 10.1109/OPTRONIX.2019.8862360

[13] RAZAVI, S. A., NESHATI, M. H. Development of a low-profile circularly polarized cavity-backed antenna using HMSIW technique. IEEE Transactions on Antennas and Propagation, 2013, vol. 61, no. 3, p. 1041-1047. DOI: 10.1109/TAP.2012.2227104

[14] KUMAR, K., DWARI, S., PRIYA, S. Dual band dual polarized cavity backed cross slot half mode substrate integrated waveguide antenna. In 2017 IEEE Applied Electromagnetics Conference (AEMC). Aurangabad (India), 2017, p. 1-2. DOI: 10.1109/AEMC.2017.8325743

[15] DASHTI, H., NESHATI, M. H. Development of low-profile patch and semi-circular SIW cavity hybrid antennas. IEEE Transactions on Antennas and Propagation, 2014, vol. 62, no. 9, p. 4481-4488. DOI: $10.1109 /$ TAP.2014.2334708

[16] LAI, Q. H., FUMEAUX, C., HONG, W., et al. $60 \mathrm{GHz}$ aperturecoupled dielectric resonator antennas fed by a half-mode substrate integrated waveguide. IEEE Transactions on Antennas and 
Propagation, 2010, vol. 58, no. 6, p. 1856-1864. DOI: 10.1109/TAP.2010.2046852

[17] RAZAVI, S. A., NESHATI, M. H. Low profile H-plane horn antenna based on half mode substrate integrated waveguide technique. In 2012 20th Iranian Conference on Electrical Engineering (ICEE). Tehran (Iran), 2012 p. 1351-1354. DOI: 10.1109/IranianCEE.2012.6292567

[18] LACIK, J. Circularly polarized SIW square ring-slot antenna for X-band applications. Microwave and Optical Technology Letters, 2012, vol. 54, no. 11, p. 2590-2594. DOI 10.1002/mop.27113

[19] HUBKA, P., LACIK, J. Linearly polarized HMSIW U-slot antenna. In 2015 Conference on Microwave Techniques (COMITE). Pardubice (Czech Republic), 2015, p. 1-3. DOI: 10.1109/COMITE.2015.7120225

[20] HUBKA, P., LACIK, J. X-band circularly polarized HMSIW Uslot antenna. Radioengineering, 2016, vol. 25, no. 4, p. 687-692. DOI: $10.13164 / \mathrm{re} .2016 .0687$

[21] LAI, Q., FUMEAUX, C., HONG, W., et al. Characterization of the propagation properties of the half-mode substrate integrated waveguide. IEEE Transactions on Microwave Theory and Techniques, 2009, vol. 57, no. 8, p. 1996-2004. DOI: 10.1109/TMTT.2009.2025429

\section{About the Authors...}

Patrik HUBKA was born in Čeladná, Czech Republic, in 1987. He received his M.Sc. degree in Electrical Engineering from Brno University of Technology, Czech Republic, in 2012, and is currently working toward the Ph.D. degree in Electrical Engineering at the Department of Radio Electronics, Faculty of Electrical Engineering and Communication, Brno University of Technology. His research interests include microwave circuits based on HMSIW.

Jaroslav LÁČÍK received the M.Sc. and Ph.D. degrees from Brno University of Technology, Brno, Czech Republic, in 2002 and 2007, respectively. He is currently an Associate Professor at the Department of Radio Electronics, Faculty of Electrical Engineering and Communication, Brno University of Technology. His research interests are antennas, body-centric wireless communication, and computational electromagnetics. He is a member of IEEE. 